\title{
Seismo-Deformation Anomalies Associated with the M6.1 Ludian Earthquake on August 3, 2014
}

\author{
Chieh-Hung Chen ${ }^{1}\left(\mathbb{D}\right.$, Xiaoning Su ${ }^{2}$, Kai-Chien Cheng ${ }^{3, *}$, Guojie Meng ${ }^{2}{ }^{\mathbb{D}}$, Strong Wen ${ }^{3} \mathbb{C}$ \\ and Peng Han ${ }^{4}$ \\ 1 State Key Laboratory of Geological Processes and Mineral Resources, Institute of Geophysics and Geomatics, \\ China University of Geosciences, Wuhan 430074, China; zjq02010@cug.edu.cn \\ 2 Key Laboratory of Earthquake Forecasting, Institute of Earthquake Forecasting, China Earthquake \\ Administration, Beijing 100036, China; sxn@ief.ac.cn (X.S.); mgj@cea-ies.ac.cn (G.M.) \\ 3 Department of Earth and Environmental Sciences, National Chung Cheng University, Minsyong, Chiayi \\ County 62102, Taiwan; strong@eq.ccu.edu.tw \\ 4 Department of Earth and Space Sciences, Southern University of Science and Technology, Shenzhen 518055, \\ China; hanp@sustc.edu.cn \\ * Correspondence: cheng.168@ccu.edu.tw; Tel.: +886-5-272-9241
}

Received: 2 March 2020; Accepted: 24 March 2020; Published: 26 March 2020

\begin{abstract}
A time-frequency method retrieving the acceleration changes in the terminal stage of the M6.1 Ludian earthquake in China is discussed in this article. The non-linear, non-stationary seismo-demformation was obtained by using the Hilbert-Huang transform and followed by a band-pass filter. We found that the temporal evolution of the residual GNSS-derived orientation exhibits a unique disorder-alignment-disorder sequence days before the earthquake which corresponds well with the four stages of an earthquake: elastic strain buildup, crack developments, deformation, and the terminal stage of material failure. The disordering orientations are gradually aligned with a common direction a few days before the terminal stage. This common direction is consistent with the most compressive axis derived from the seismological method. In addition, the region of the stress accumulation, as identified by the size of the disordered orientation, is generally consistent with the earthquake preparation zones estimated by using numerical models.
\end{abstract}

Keywords: Ludian earthquake; deformation; GNSS

\section{Introduction}

The Global Navigation Satellite System (GNSS) has been utilized to monitor long-term movements of plates and deformation of the crust associated with earthquakes [1-4]. Since increasing observations generally improves the accuracy [5,6], the daily solutions of many continuous GNSS (cGNSS) stations processed by software like GAMIT/GLOBK and Bernese GPS have been demonstrated to the level of $\sim 2$ and $\sim 4 \mathrm{~mm}$ in the horizontal and vertical components, respectively. Seasonal variation due to various frequency-dependent signals dominates the time series of the GNSS daily solution, including atmospheric loading, continental water-storage loading, and non-tidal ocean loading $[2,7,8]$ and other sources such as the thermal expansion of monuments and mis-modeled effect of orbits [9]. After a careful removal of jumps and the annual and semi-annual variations from the original time series, a reliable trend representing the velocity of the dominant plate movements can be obtained with the accuracy of $<1 \mathrm{~mm} /$ year with the data span of several years [10]. Mapping the velocity field using multiple stations is important for studies in earthquake hazards, tectonics, crustal deformation, seismology, ionosphere, precipitable water vapor (PWV), soil moisture, and others. These studies span a wide range of fields in the Earth's spheres. On the other hand, the time-frequency methods, 
e.g., the Fourier transform, wavelets and the Hilbert-Huang Transform (HHT) [11,12] are also capable of separating the unwanted disturbance from the originals with filters of different bands and thus improve the interpretation $[13,14]$.

The Ludian earthquake $\left(103.4^{\circ} \mathrm{E}, 27.2^{\circ} \mathrm{N}\right)$ with the moment magnitude $(\mathrm{Mw})$ of 6.1 occurred in China on 3 August 2014 (Figure 1). The data of a cGNSS array of about 300 stations covering an area of approximately $3500 \times 3000 \mathrm{~km}^{2}$ is analyzed with the HHT in order to study the temporal evolution of the non-linear, non-stationary earthquake-induced signals related to the stress accumulation, and thus the potential earthquake preparation zone of the event. Note that the 260 cGNSS station used in this study are installed by China Earthquake Administration and they also belong to the Crustal Movement Observation Network of China (CMONOC). The rest of the stations located at surrounding Mainland China are retrieved from Nepal continuous GPS network and IGS networks.

(a)

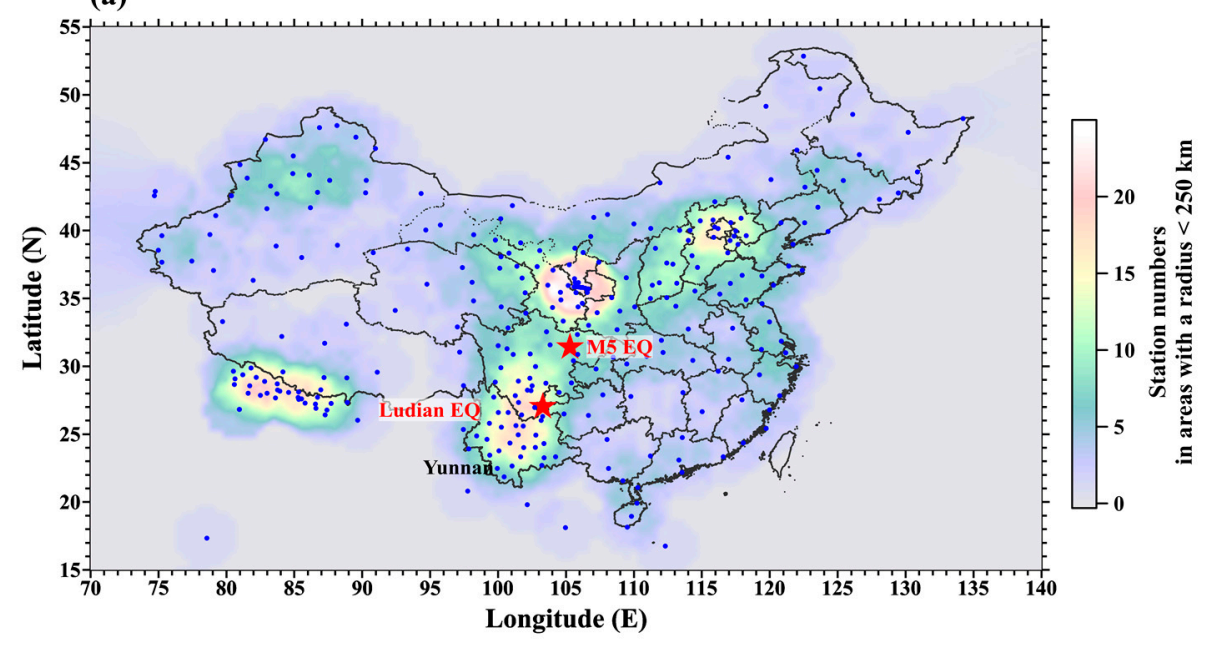

(b)
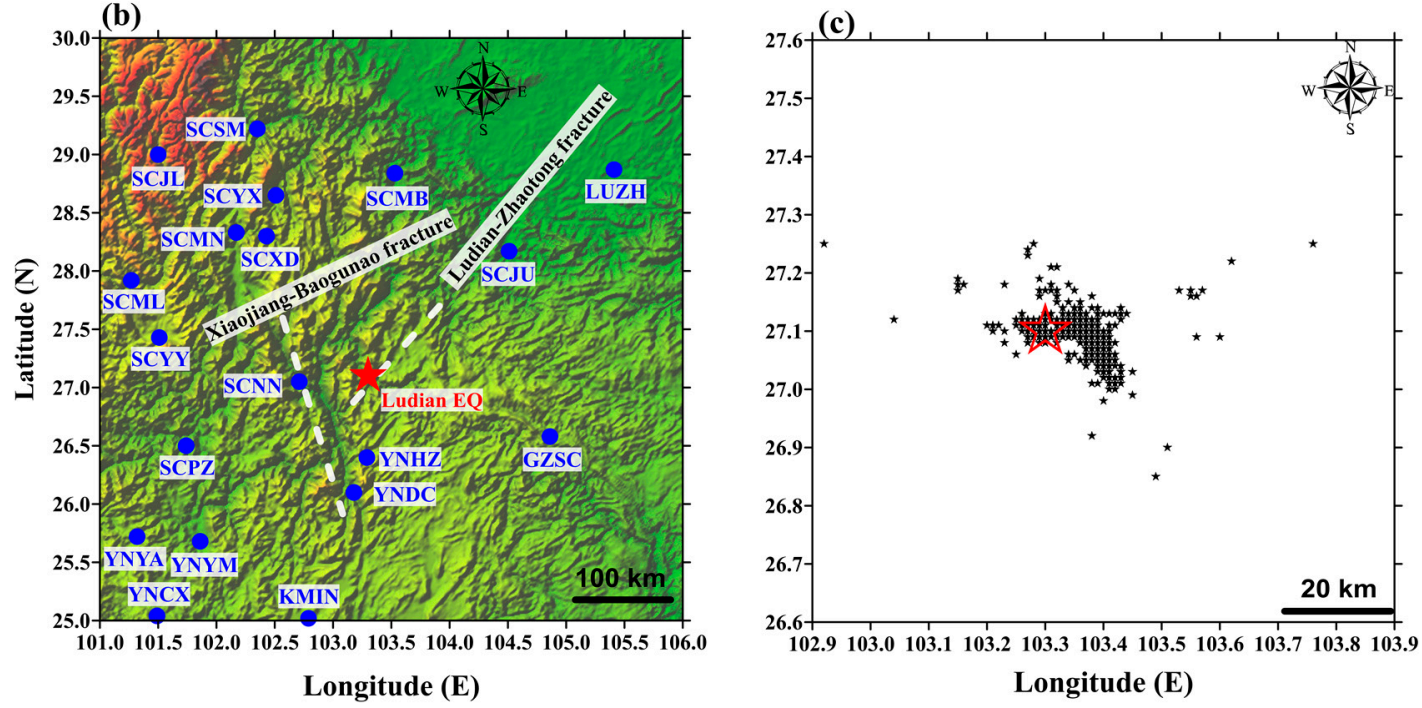

Figure 1. Locations of the cGNSS stations in China used in this study and the aftershocks associated with the Ludian earthquake. (a) Locations of the cGNSS stations and the station density map in China. The density is constructed by the number of stations within a spatially moving window with a radius of $250 \mathrm{~km}$. Two earthquakes discussed in this study are denoted by red stars. (b) reveals the cGNSS stations located around the epicenter. White dash lines denote the Ludian-Zhaotong and Xiaojiang-Baogunao fracture zones. The background digital elevation model is the ETOPO1 Global Relief Model [15]. (c) Distributions of the aftershocks associated with the Ludian earthquake. The red star is the epicenter of the Ludian earthquake and the black stars the epicenters of the aftershocks. 
In this study, we calculated surface deformation within a time span from 2012 to 2015 . The surface deformation of the stations near the epicenter was compared to the distant ones by calculating the cross coefficient in order to quantify the abnormal variations. The HHT was used to filter out the long-term secular tectonic movement, the seasonal (including annual and semi-annual) and the short-term noise from the time series. As a result, the behavior of crust deformation in the terminal stages of failure can be revealed. In addition, the orientations of the frequency-dependent deformed vectors were compared to the most compressive axis of the Ludian earthquake derived from the Global CMT project to confirm that the retrieved signals are seismogenic due to the stress accumulation in the crust. The temporal evolution of the frequency-dependent deformation can be examined to explain the unusual distribution of the aftershocks and to determine the size of the earthquake preparation zone.

\section{Materials and Methods}

In order to efficiently retrieve the seismo-deformation signals shortly before an earthquake, an empirical relationship describing the terminal stage of failure under the condition of constant stress and temperature [16,17] is employed. This relationship is related to the general constitutive laws in damage-mechanics models [18]. The empirical relationship is expressed as

$$
\dot{\Omega}^{-\alpha} \ddot{\Omega}-A=0,
$$

where $\Omega$ is an observation (e.g., strain or displacement) and A and $\alpha$ are empirical constants. The dots denote the time derivatives. When $\alpha$ is close to 2 , it implies that the acceleration changes in $\Omega$ is approaching the terminal stage. This empirical relationship provides a useful description of creep and deformation before landslides and volcanic eruptions [19] and it is related to the general constitutive laws used commonly in damage-mechanics models [18]. Stress accumulates in the crust and gradually approaches the threshold of fault rupture shortly before an earthquake. The process is related to the terminal stage of failure and thus, the quantity represented by $\Omega$ can be strain or displacement of rocks or soils.

In order to retrieve the acceleration changes of crustal deformation in the terminal stage of the fault failure, data of about 300 cGNSS stations in continental China well covering the areas around the Ludian earthquake was collected. We processed the daily solution of these stations using GAMIT/GLOBK software with a 24-hour ionosphere-free combination to fix the ambiguities. We adopted the precise orbits from the International GNSS Service for Geodynamics (IGS), the precise EOPs from the IERS Bulletin B, and the IGS tables for phase center of the antennae. We estimated one tropospheric zenith delay and two horizontal gradients of that at each station every 2 hours each day. The resulting daily solutions are stacked and loosely constrained in the International Terrestrial Reference Frame (ITRF2008) to a set of global stable stations released by the Scripps Orbital and Permanent Array Center [20].

Earthquake-related acceleration changes in the temporal domain is generally parabolic, which is non-linear. To examine the existence of the empirical relationship in crustal deformation before earthquakes, a linear trend is removed from the daily solutions of the cGNSS data to enhance the acceleration changes. The acceleration changes can be observed from the daily solutions of the cGNSS data once a linear trend is removed. The following processes are utilized to retrieve the acceleration changes for further examining the relationship between the acceleration changes and earthquakes parameter. Note that the acceleration changes are non-stationary due to the mature of the discontinuous occurrence of an earthquake. The HHT is suitable in this case since it preserves the non-linearity of the time series. It is utilized in this study to extract the non-linear and non-stationary features in the cGNSS time series. However, the parabolic variation of an acceleration change is not frequency-dependent, so it covers a very wide band in the frequency domain. To overcome this, a band-pass filter of 20-150 days was employed to retrieve the acceleration changes from the cGNSS time series [21]. 
The HHT comprises two major processes: the Empirical Mode Decomposition (EMD) and the Hilbert-transform (HT). The EMD process decomposes time series into many Intrinsic Mode Functions (IMFs) and a residual based on the characteristics of signal energy. The residual is generally considered to be the long-term trend of the time series with no significant frequency characteristics, while each IMF is considered as the instantaneous frequency and amplitude at each observed epoch. When using HHT to study the crustal deformation, the residual is the long-term plate tectonic movements [22,23], whereas the IMFs are the frequency-dependent components which represent the nature of the deformation with the long-term tectonic movements removed. The "filtered GNSS data" hereafter denotes the observed cGNSS deformation time series with the residual (the long-term tectonic movements) and the frequency-dependent IMFs (the frequency-dependent factors common to all stations such as annual, semi-annual and seasonal variations and noise) removed. It reveals the abnormal acceleration changes approaching the terminal stage. Notably, the processes regarding the removal of the residual and the frequency-dependent components can be simplified by using a band-pass filter of 20-150 days via HHT in the frequency domain [21].

The orientations of the filtered GNSS data, or the "GNSS-azimuth" thereafter, are further computed. In general, the GNSS-azimuth of all stations in an area exhibits random-like disordering due to the removal of the long-term tectonic movements, so one cannot find a definite common orientation for all stations. At this point, the abnormal acceleration change is insignificant. When the earthquake-related stress accumulates, as the crust gradually approaches the terminal stage of material failure, the abnormal acceleration change starts to dominate and the disordered GNSS-azimuth of stations starts to align to a common direction, indicating the existence and the influence of the accumulated stress. The alignment becomes disordered once again when the earthquake preparation is finished at the terminal stage.

\section{Results}

Figures $2-4$ are the NS, EW and vertical components of the GNSS data at the stations (listed in Table 1) within $2.5^{\circ}$ from the epicenter after the removal of a linear trend with the empirical relationship (1) to examine the existence of the acceleration changes. The data in the NS component (Figure 2) shows an acceleration change toward the north in most of the stations during 2014.15-2014.32 due to unknown factors. Variations of the data became smooth after 2014.32, except for abnormal short-term event at about 2014.5. This short-term event is an unusual increase at 2014.48 and an abnormal decrease at 2014.5 at most stations $200 \mathrm{~km}$ within the epicenter. To quantify the difference between the data during the short-term event, the cross correlation (CC) methods were utilized. YNCX was selected as the reference and the CC values were computed using two reference windows of 2013.45-2013.58 (i.e., 366-415 days before the EQ) and 2014.31-2014.44 (51-100 days before the EQ) and additionally, one monitoring window of 2014.45-2014.58 (1-50 days before the EQ) was selected. As can be seen in Figure $5 \mathrm{a}$, the $\mathrm{CC}$ values derived from the two reference windows are mainly inversely proportional to the epicentral distance. The correlations of station pairs in these two windows are between 0.7-0.8. This implies that the data are highly correlated at the station pairs during these 2 reference windows. In contrast, the correlation derived from the monitoring window, 1-50 days before the Ludian earthquake, is generally smaller than 0.6 . The significantly smaller CC values suggest that the GNSS data after the removal of a linear trend are potentially affected by the earthquake-related stress 50 days before the mainshock. 


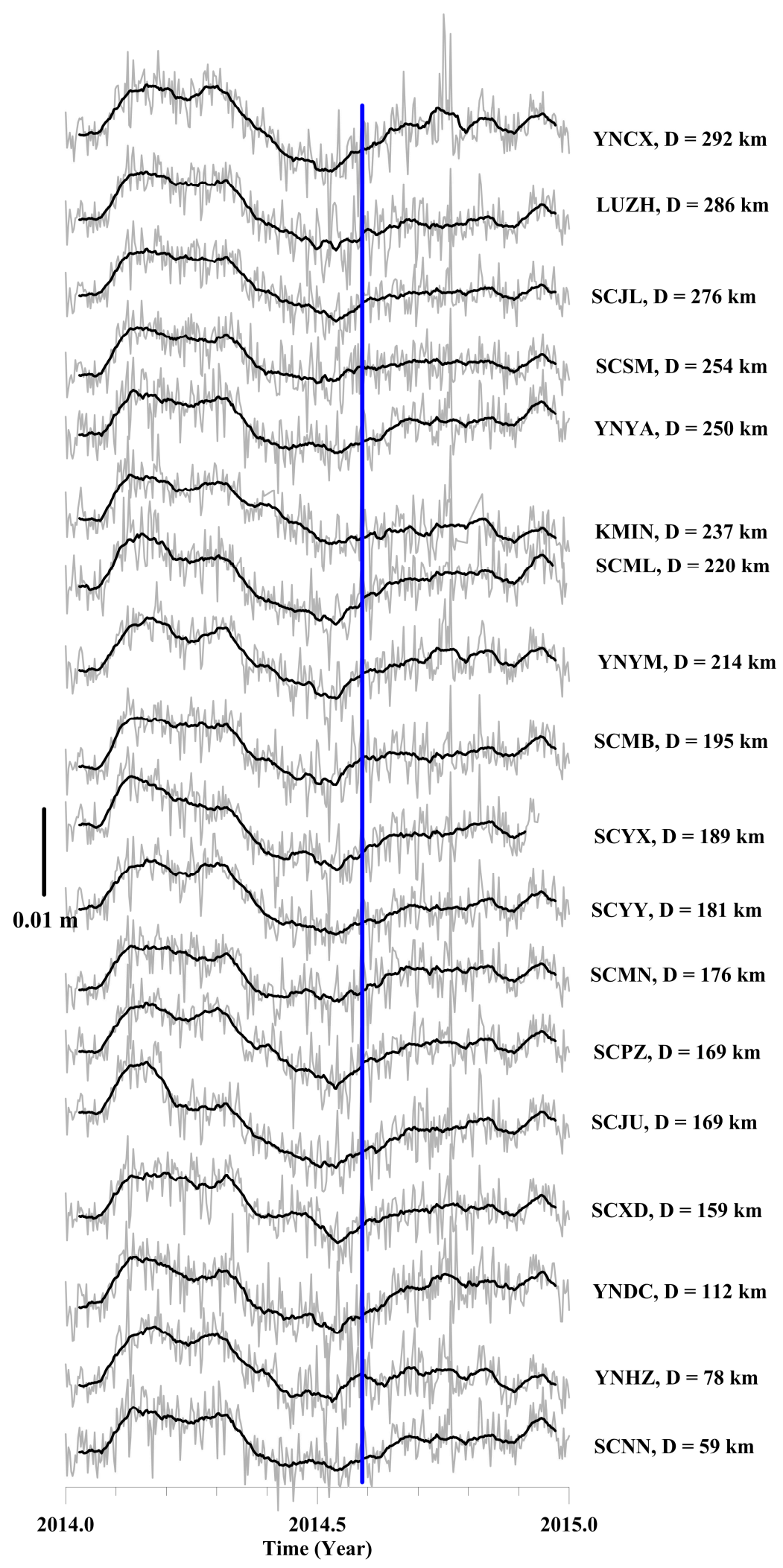

Figure 2. The NS component of the GNSS data (in gray) for the stations with the epicentral distance $<300 \mathrm{~km}$ after the removal of a linear trend. The black lines denote the result of a 20-day moving average. The blue vertical line indicates the time of the Ludian earthquake. 


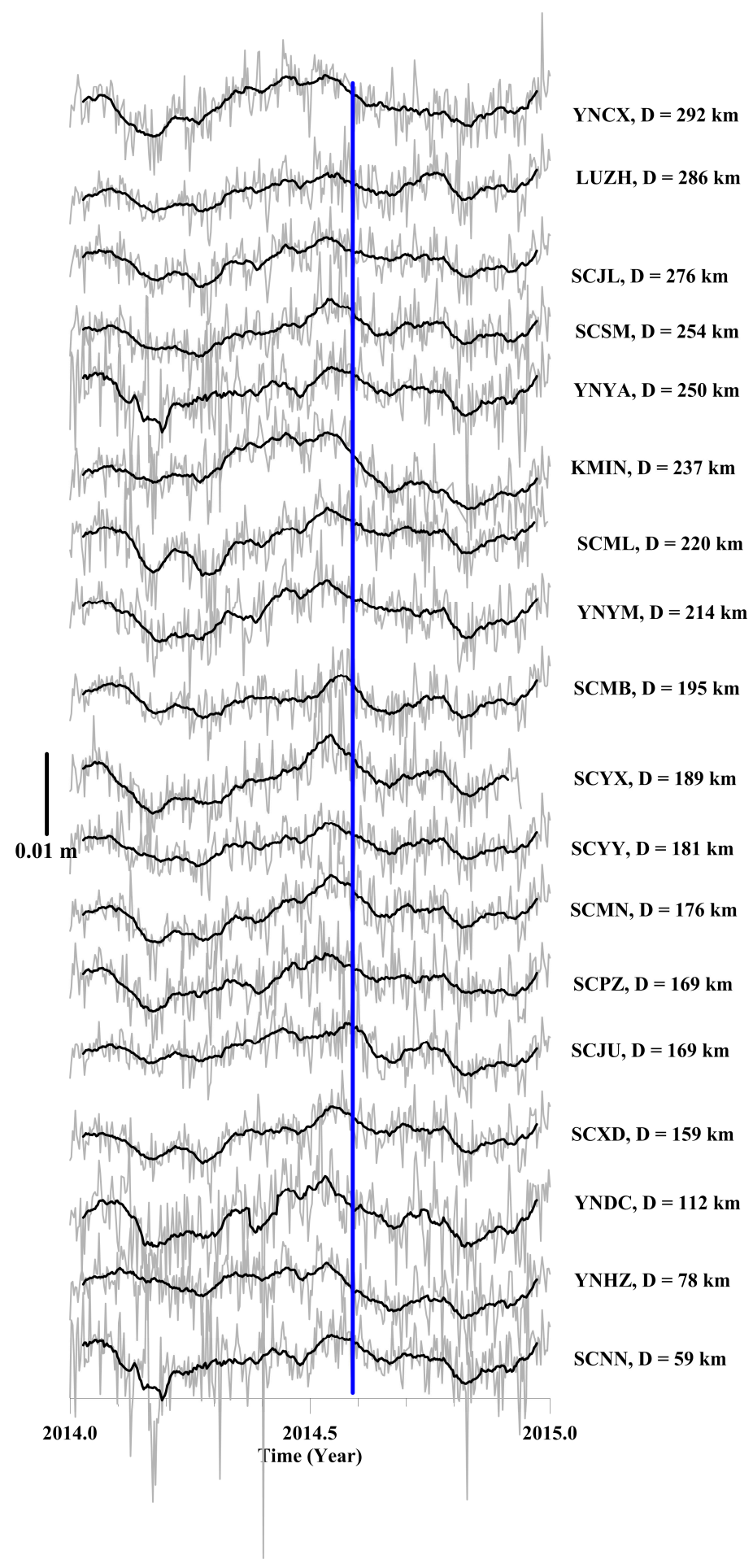

Figure 3. The EW component of the GNSS data (in gray) for the stations with the epicentral distance $<300 \mathrm{~km}$ after the removal of a linear trend. The black lines denote the result of a 20-day moving average. The blue vertical line indicates the time of the Ludian earthquake.

Regarding the EW component, a few periodic vibrating cycles (with an amplitude of $0.005 \mathrm{~m}$ and a duration of approximately 40 days) can be found during 2014.0-2014.5. A significant eastward acceleration changes were observed at most stations from 2014.15 to 2014.58, though the highest peak at each station does not appear at the same time. Sharp inverse changes were observed at YNHZ, YNDC, SCYX, YNYM, SCML and SCSM. The time-shift anomalies appeared on the data at the 
SCXD, SCPZ, SCJU and SCMB stations. A step was observed at the YNDC station before the Ludian earthquake. Nevertheless, the general trend of the abnormal changes can be observed from the data at the most stations $200 \mathrm{~km}$ within the epicenter. The CC values of the data in the EW component are mainly between 0.5 and 0.7 (Figure 5b). These smaller CC values suggest that the variations of the data in those station pairs are partially independent. When we consider the results derived from the monitoring windows (i.e., 1-50 days before the mainshock), the CC values are similar to those stations with the epicentral distance either less than $169 \mathrm{~km}$ or larger than $200 \mathrm{~km}$. Regarding the CC values obtained from the data recorded by the station with the epicenter distance between $169 \mathrm{~km}$ and 200 $\mathrm{km}$, a significant drop of about -0.15 can be found. This suggests that the earthquake-related stress affected the cGNSS data of the EW component and thus reduced their correlation.
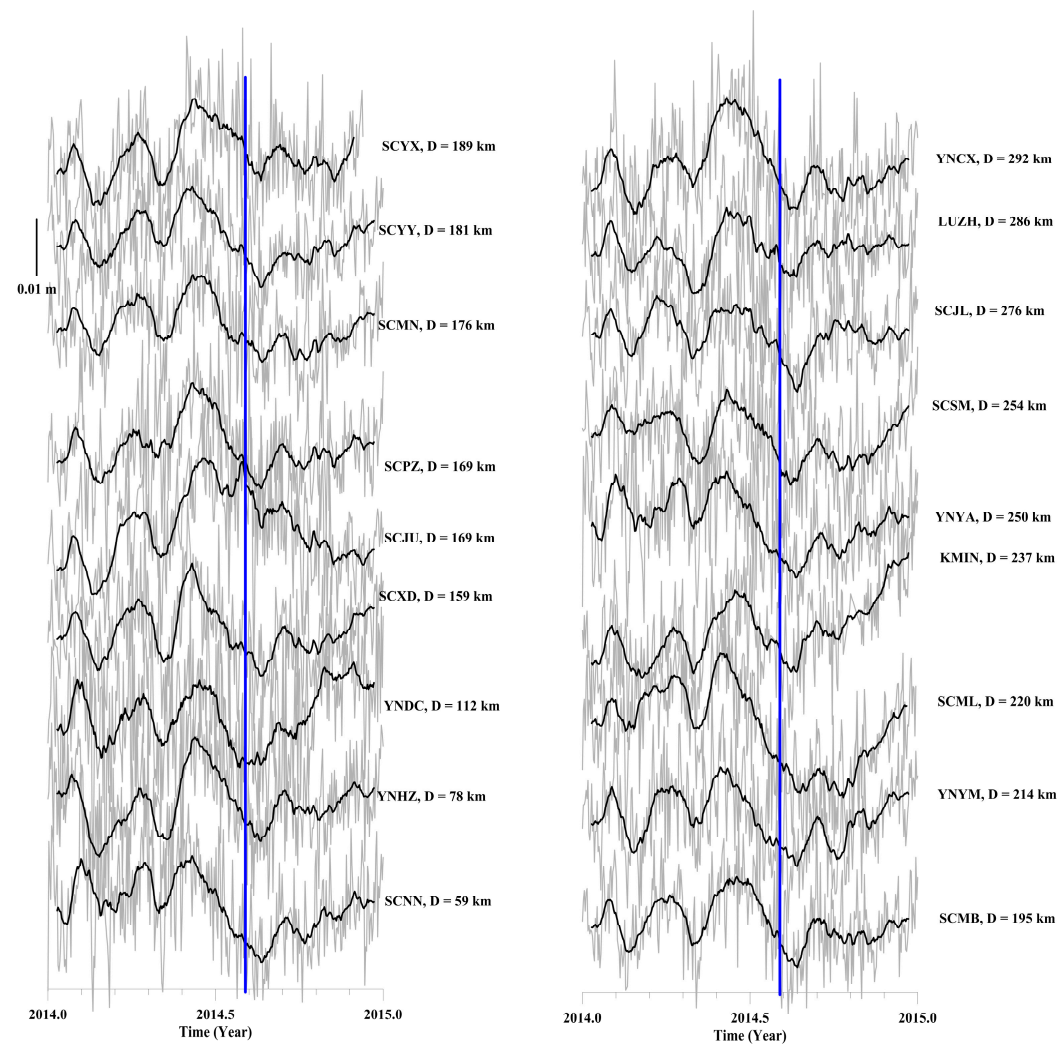

Figure 4. The vertical component of the GNSS data (in gray) for the stations with the epicentral distance $<300 \mathrm{~km}$ after the removal of a linear trend. The black lines denote the result of a 20-day moving average. The blue vertical line indicates the time of the Ludian earthquake.

Larger fluctuations (approximately 0.01-0.02 $\mathrm{m}$ ) in the vertical component can be found a few months before the earthquake (Figure 4). The vertical component of each stations generally shows in-phase variation at most stations. Three obvious cycles can be found from 2014.0 to 2014.58. The significant abnormal changes with an amplitude of about $0.02 \mathrm{~m}$ can be found at the SCJU station, which is located $169 \mathrm{~km}$ away from the epicenter of the Ludian earthquake. The abnormal changes with relatively-small amplitude can also be observed from the data at most stations. In terms of the $\mathrm{CC}$ values examined via the two reference windows in Figure 5c, the values are between 0.5 and 0.8. No significant difference was found from the values derived from the reference and monitoring windows. The smaller correlation (about 0.05 less) could be caused by either the temporal window or artificial noise. Thus, the cGNSS data on the vertical component are not utilized in the following analysis, only the horizontal ones are analyzed further. In short, the acceleration changes can be found from the cGNSS data after the removal of a linear trend. The relative-small CC values suggest the existence of crustal deformation close to the epicenter several days before the occurrence of the Ludian 
earthquake, particularly on the NS and EW components of the cGNSS data. However, the acceleration changes are not unusual and can be frequently found from the cGNSS data. The anomalous deformation is very difficult to be directly retrieved from the daily solutions (Figures 2-4).

Table 1. The latitude and longitude of the cGNSS stations with $2.5^{\circ}$ to the epicenter.

\begin{tabular}{ccc}
\hline Station (code) & Latitude (N) & Longitude (E) \\
\hline YNCX & 25.05 & 101.49 \\
\hline LUZH & 28.87 & 105.41 \\
\hline SCJL & 29.01 & 101.50 \\
\hline SCSM & 29.23 & 102.35 \\
\hline YNYA & 25.72 & 101.33 \\
\hline KMIN & 25.03 & 102.80 \\
\hline SCML & 27.93 & 101.28 \\
\hline YNYM & 25.69 & 101.86 \\
\hline SCMB & 28.84 & 103.53 \\
\hline SCYX & 28.65 & 102.51 \\
\hline SCYY & 27.43 & 101.51 \\
\hline SCMN & 28.33 & 102.17 \\
\hline SCPZ & 26.50 & 101.74 \\
\hline SCJU & 28.18 & 104.52 \\
\hline SCXD & 28.30 & 102.44 \\
\hline YNDC & 26.11 & 103.18 \\
\hline YNHZ & 26.41 & 103.29 \\
\hline SCNN & 27.06 & 102.72 \\
\hline
\end{tabular}

Here, we take the GNSS data on the NS and EW components at the SCNN station as an example to illustrate the removal of the unwanted influences (i.e., the short-term noise, semi-annual and annual variations and long-term plate movements) using a band-pass filter of 20-150 days via HHT (also see Chen et al., 2020 [24]) to further examine the relationship between the acceleration changes and parameters of earthquakes. Figure 6a,c present the NS and EW components of the daily solution at the SCNN station from 2012 to 2015. Significant semi-annual variations along with a long-term southward trend can be found on the NS component in Figure 6a. In contrast, annual variations along with a long-term eastward trend can be observed on the EW component in Figure 6c. When these data are filtered with HHT, the unwanted influences are clearly removed from the filtered GNSS data (Figure $6 \mathrm{~b}, \mathrm{~d}$ ). Note that the amplitude of the filtered data on the NS and EW component is about $8 \mathrm{~mm}$ and $10 \mathrm{~mm}$ during 2012-2015, respectively. The NS and EW components of the filtered data are further utilized to compute the GNSS-azimuth to understand the seismo-deformation associated with the Ludian earthquake. We computed the average difference of the GNSS-azimuths around the Ludian area by using every two stations located within the epicentral distance $<300 \mathrm{~km}$, (i.e., the 18 stations listed in Table 1) during 2012-2015 (Figure 6e). The larger average GNSS-azimuth difference implies that the orientation of the anomaly at these 18 stations are not common, that is more disordered, whereas the smaller difference indicates they are roughly aligned to a general azimuth. We focused on the changes of the average difference before the occurrence of the Ludian earthquake. The difference is about $90^{\circ}$ 30 days before the Ludian earthquake and gradually decreases to $30^{\circ} 15$ days before the event. Then, the difference increases again a few days before the Ludian earthquake. The entire temporal evolution of the average GNSS-azimuth forms a unique disorder-alignment-disorder sequence before the Ludian earthquake. Not only can be seen in the Ludian earthquake, this unique disorder-alignment-disorder sequence can also be found in other events around the Ludian area (Figure 6e). The unique sequence observed in this study also agrees with the observation in the previous studies [21-24]. However, earthquake occurrence does not follow the sequence and no event is detected after the sequence that can be found during the study period. 


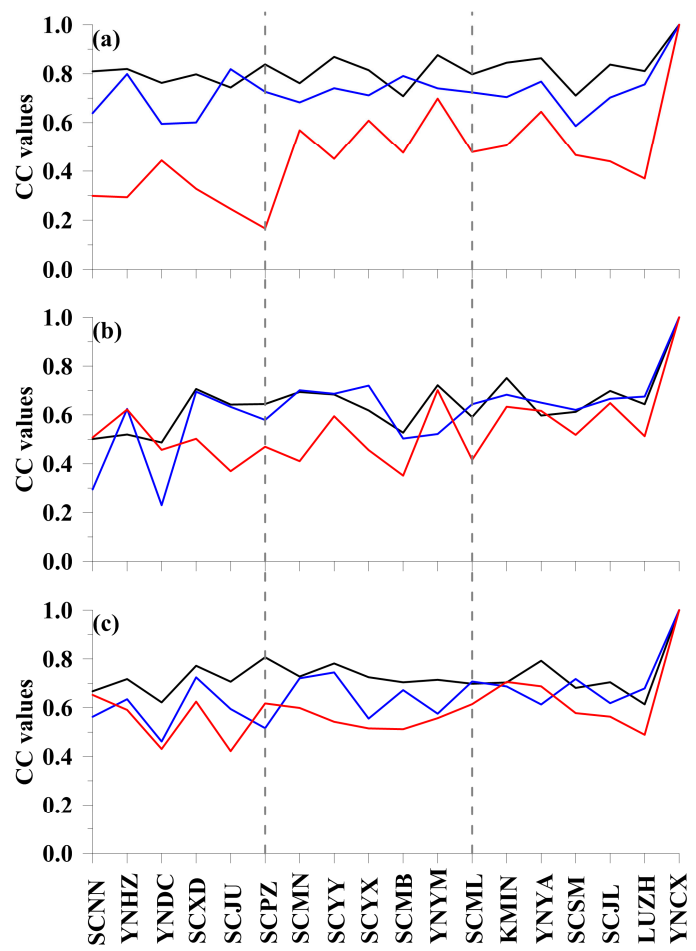

Figure 5. The cross correlation (CC) values versus to the epicentral distances for the NS (a), ES (b), and the vertical (c) components of the filtered GNSS data. The black and blue lines denote the two reference windows, namely, 366-415 days and 51-100 days before the Ludian earthquake. The red line is the monitoring window (1-50 days before the earthquake). YNCX is the reference station so its CC values remains as 1 . The vertical dash line to the left approximately corresponds the epicentral distance of 220 $\mathrm{km}$ (from SCPZ to YNCX), and the one to the right, $169 \mathrm{~km}$ epicentral distance (from SCML to YNCX).

To examine whether the aligned GNSS-azimuths are useful crustal displacement information before earthquakes around the Ludian area, statistical tests of the Molchan's error diagram is performed in this study. The Molchan's error diagram is a conventional method to evaluate the prediction performance of given observations for earthquake forecasting. It shows the rate of earthquakes successfully detected against the rate of alarmed cells [25,26]. Figure 7a shows the Molchan's error diagram of the optimal prediction strategy based on the average difference of the GNSS-azimuths related to earthquakes with magnitude $\geq 5$ around the Ludian area during 2012-2015. The prediction curve (the bold red line) is obviously over the random prediction line (i.e., the black diagonal line). Most perdition curve are comparable with the $90 \%$ confidence interval, and quite a few even exceed the $95 \%$ confidence interval. Considering the earthquakes with magnitude $\geq 5.5$ during the same temporal period, the prediction curve is generally over the $95 \%$ confidence interval (Figure $7 \mathrm{~b}$ ). Meanwhile, a great result with the alarm rate of $\sim 0.35$ and the detection rate of $\sim 0.72$ can be obtained that is significantly larger than $95 \%$ confidence interval. These results suggest that the aligned GNSS-azimuths used in this study provide useful crustal displacement information before earthquakes and are beneficial to earthquakes when predicting earthquakes with relatively larger magnitude.

Figure 8 reveals the GNSS-azimuth distribution from July 5 to August 2 in 2014 associated with the Ludian earthquake. No aligned GNSS-azimuths in a large scale can be found on 5 July 2014 (i.e., 29 days before the Ludian earthquake) because the long-term plate tectonic movements have been removed. Those disordered GNSS-azimuths were gradually turned to a common direction toward the southeast and this can be seen in the inset for 9 July 2014 in Figure 8. Two circle-like regions located at $\left(30^{\circ} \mathrm{N}, 107^{\circ} \mathrm{E}\right)$ and $\left(25^{\circ} \mathrm{N}, 100^{\circ} \mathrm{E}\right)$ are surrounded by the aligned GNSS-azimuths on 18 July 2014 . The phenomenon of surroundings became clear for the region $\left(25^{\circ} \mathrm{N}, 100^{\circ} \mathrm{E}\right)$ on 23 July 2014. Areas with aligning GNSS-azimuths gradually decreased on 20 July 2014. Notably, 
disordered GNSS-azimuths regions remain at the epicenters of the M5 earthquake $\left(31.45^{\circ} \mathrm{N}, 105.30^{\circ} \mathrm{E}\right)$ on 29 July 2014 and the Ludian $\left(27.2^{\circ} \mathrm{N}, 103.4^{\circ} \mathrm{E}\right)$ earthquake on 3 August 2014. After the occurrence of the M5 earthquake, the increase of disordered regions reached to the maximum on 2 August and the Ludian earthquake occurred one day thereafter. The analytical results suggest that non-linear abnormal changes in the cGNSS data shown in Figures 2-4 can be effectively retrieved by using the HHT. The disorder-alignment-disorder sequence shown in Figure 6e can be repeatedly observed in the spatial domain in Figure 8. Meanwhile, the sequence (Figures 6e and 8) agrees with the observations of earthquakes in Japan and the Taiwan region [21-24].

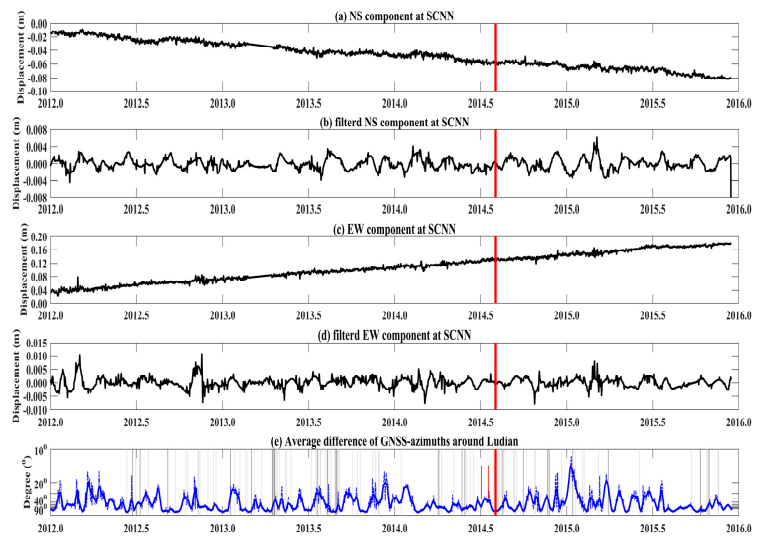

Figure 6. The daily solution and the filtered GNSS data on the NS and EW components at the SCNN station and the average difference of GNSS-azimuths around the Ludian area. (a) is the daily solution of the GNSS data in the NS direction, whereas (b) is the filtered result of (a) using HHT. Similarly (c) is the daily solution of the GNSS data in the EW direction, whereas (d) is its filtered result using HHT. (e) shows the average difference of the GNSS-azimuths among the stations listed in Table 1 around the Ludian area. The blue dash and solid lines denote the daily difference and the smooth curve using a 10 days windows. Grey and dark vertical lines show occurrence time of the $M>=4$ and $\mathrm{M}>=5$ earthquakes within $\left(95^{\circ}-110^{\circ} \mathrm{E}, 25^{\circ}-35^{\circ} \mathrm{N}\right)$. Note that earthquake catalog was retrieved from the archive of China Earthquake Administration. The thick red line indicates the occurrence time of the Ludian earthquake. The thin red lines before the Ludian earthquake mark 15-day temporal intervals for reference.
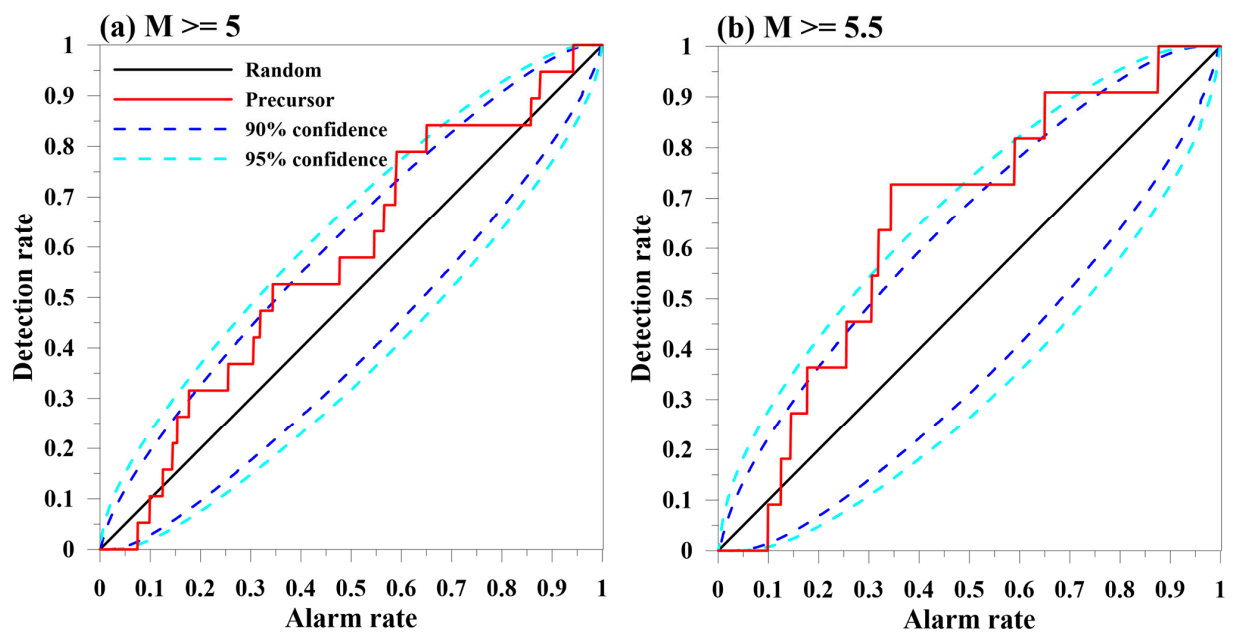

Figure 7. The Molchan's error diagram of the optimal prediction strategy for the GNSS-azimuth related to $M \geq 5$ earthquakes in (a) and $M \geq 5.5$ earthquakes in (b). 

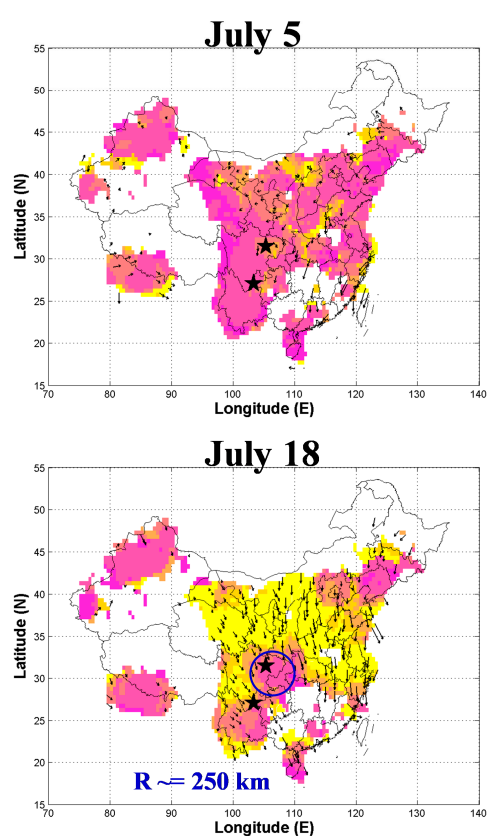

July 23

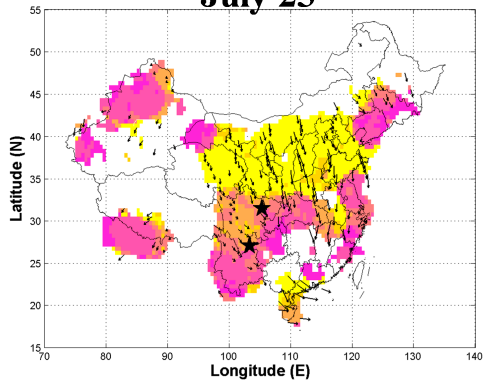

July 28

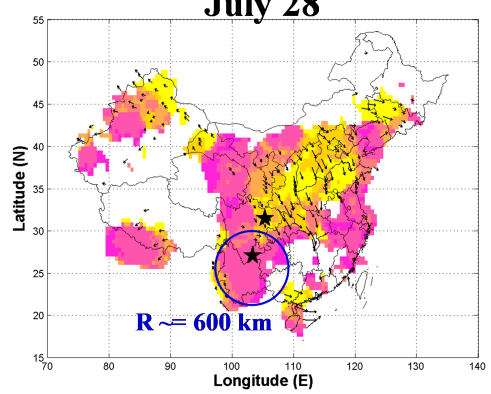

July 9

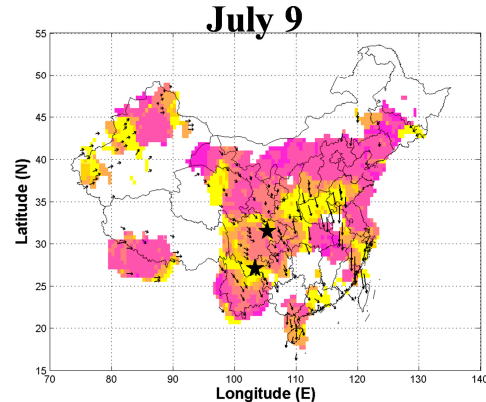

July 20

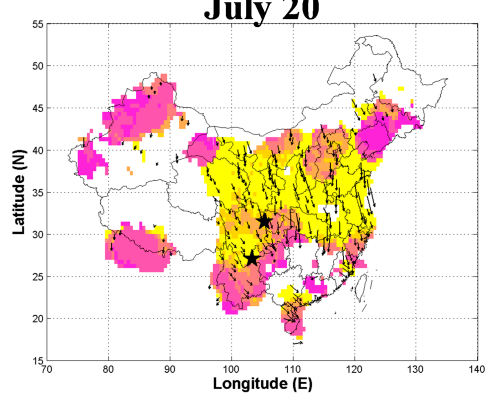

July 27

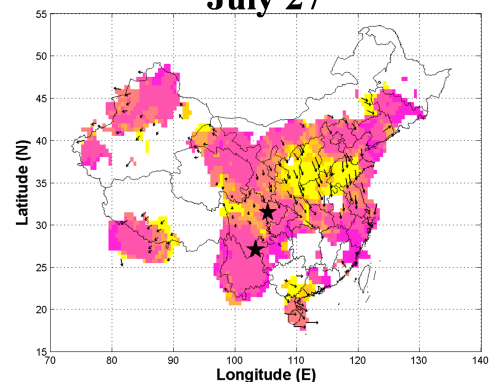

July 30

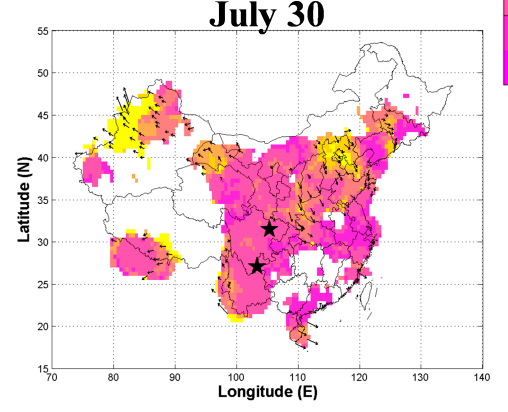

Aug. 2

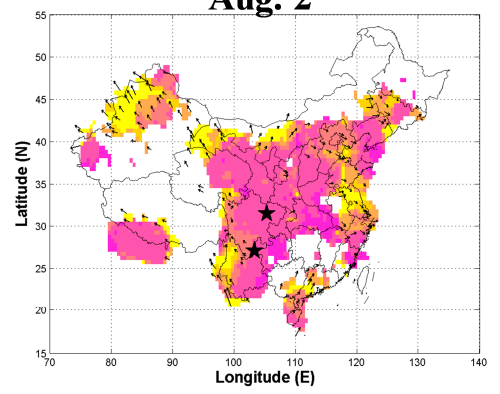

Figure 8. The episodic distribution of average difference of the GNSS-azimuths associated with the M5 and the Ludian earthquakes, whose epicenters are denoted by the black stars. The color indicates the angular difference of the GNSS-azimuths at a given location with respect to the average of the neighboring stations within a $2.5^{\circ} \times 2.5^{\circ}$ window. When the difference is less than $50^{\circ}$, a general common direction is illustrated with arrows. 


\section{Discussion}

Changes in physical parameters during an earthquake are commonly divided into four stages: Buildup of elastic strain, dilatancy and crack development, unstable deformation in the fault zone, and a sudden stress drop followed by mainshocks [17]. For a strike-slip fault, straight lines can be easily identified across both sides of a fault and they remain parallel in the first stage of elastic strain buildup. In the stage of dilatancy and crack development, these lines are bent when the stress continues to accumulate in the crust forming a locked region somewhere in the focal area. The bending temporally stops due to the unstable deformation triggered by the accumulated stress when it approaches the terminal stage of the fault rupture. After the mainshock, the accumulated stress rapidly drops. We noticed that there are disordered GNSS-azimuths retrieved from the filtered GNSS data 29 days (i.e., July 5) before the Ludian earthquake, suggesting that the earthquake-related stress is in the first stage of elastic strain buildup. Then, during the period of 25-11 days before the Ludian earthquake (i.e., July 9-23), the stress accumulation continues and cracks start to develop causing the dilatancy of the crust, so the disordered GNSS-azimuths become aligning to a certain common direction. The most compressive axis of the M5 earthquake and the Ludian earthquake is about $187^{\circ}$ and $295^{\circ}$, respectively, which are computed by using the standard method [27]. Interestingly, the alignment of the GNSS-azimuths with orientations was ranging about $170^{\circ}-180^{\circ}$ and $270^{\circ}-330^{\circ}, 2$ days before the M5 and the Ludian earthquake, respectively. This finding matches surprisingly well with the direction of the most compressive axis of these two earthquakes. The stress dominates the deformation with the NS and the EW orientations in the earthquake-related areas that could reasonably cause the aftershocks to distribute in the NS and EW directions, simultaneously (Figure 1c). Regarding the third stage, there's no significant ground uplifts and tilts observed in the area from July 18-27 for the M5 earthquake and July 20-August 2 for the Ludian earthquake. This agrees with the disordered GNSS-azimuth we found in the same periods. This is about 1-5 days before the earthquake (i.e., July 30-August 2 ) and is the stage when the abnormal changes in strainmeters, groundwater level, water temperature and radon concentration started to be noticed and reported [28]. In summary, the development of the disorder-alignment-disorder sequence we found in the GNSS-azimuth agrees with the four stages of seismo-deformation of an earthquake.

Studies have suggested that the crustal deformation can originate from atmospheric pressure during typhoons and heavy rainfall [29]. We retrieved the time series of the NS and EW displacements at the KUNM station, which is the closest one (about $250 \mathrm{~km}$ ) to the Ludian area in the Global Geophysical Fluids (GGFC) Service of IERS [30], to clarify the induced atmospheric pressure and water mass loadings. The induced atmospheric pressure and water mass loadings are mainly in the ranged between $-0.5 \mathrm{~mm}$ and $0.5 \mathrm{~mm}$ at the KUNM station that is significant smaller than the amplitude of $\sim 8 \mathrm{~mm}$ for the NS and $\sim 10 \mathrm{~mm}$ for the EW component of the filtered GNSS data at the SCNN station (Figure 6b,d). In addition, based on [29], when atmospheric pressure decreases $50 \mathrm{HPa}$, a volumetric strain increases about 100 nanostrain, that is $1 \mathrm{~mm}$ over $10 \mathrm{~km}$, at the typhoon center as verified by borehole strainmeter in Taiwan. Typhoon Rammasun was formed on the Pacific Ocean on July 11 and disappeared in Yunnan, China on July 20 in 2014. The minimum distance between the epicenter and the typhoon is about $450 \mathrm{~km}$ on July 20 while the atmospheric pressure at the typhoon center is reported as $998 \mathrm{HPa}$ [31]. Considering the normal atmospheric pressure of 1,013 $\mathrm{HPa}$, the atmospheric pressure drops $15 \mathrm{HPa}$, which roughly corresponds to 30 volumetric nanostrain at the typhoon center according to [29]. Considering the epicenter of Ludian Earthquake is $450 \mathrm{~km}$ away from the typhoon center with much smaller atmospheric pressure change, the possible effect on the crustal deformation caused by atmospheric pressure change would be negligible and mostly in the vertical. However, the GNSS-azimuths were calculated with horizontal components. In addition, the effect of atmospheric pressure change is almost immediate as mention above, but the seismo-deformation we detected lasts longer. On the other hand, Zeng et al. (2015) [28] reported that the rainfall around the Ludian area is mainly concentrated on July 13-16. However, the aligned GNSS-azimuths in a large area can be observed on July 18. The increase of disordered regions associated with the Ludian earthquake is 
mainly from July 9 to August 2 which does not correspond to the rainfall. In short, the temporal discrepancy suggests that the seismo-deformation observed in the study is unlikely to be resulted from the typhoon or the rainfall.

A strong spatial correlation among GNSS stations of a network results in a common position movement (a few $\mathrm{mm}$ ) of nearly entire network. It is called the common-mode error (CME). A regional filter or a stacke-and-remove procedure are the common mitigations [1,3]. The CME is revealed by the apparent seasonal (annual and semiannual) variation, $\sim 40 \%$ of whose power can be explained by contributions of mass redistribution [32]. Its causes are still unclear, but the consensus is that they are related to the changes in environmental mass redistribution, including atmospheric loading, continental water-storage loading, and non-tidal ocean loading $[2,7,8]$. Other potential candidates include thermal expansion of monuments [32,33], mis-modeling in orbits, antenna phase centers, reference frames, EOP (Earth Orientation Parameters), and systematic errors due to the choice of processing centers [9]. A close look with GNSS stations in the North American and Pacific plates suggests that the cross correlation among GNSS stations within $1000 \mathrm{~km}$ is 0.95 and it goes to 0 gradually as the distance increases and reaches $6,000 \mathrm{~km} \mathrm{[4]}$. The CC values are comparable regardless of the epicentral distance during the normal time (i.e., 366-415 days and 51-100 days before the Ludian earthquake) and are inversely proportional to the epicentral distance at 1-50 days before the earthquake (Figure 5). This implies that the low CC values are not dominated by the CME but earthquake-related stress changes. Notably, the alignments of the GNSS-azimuths distribution areas exceed $500 \mathrm{~km}$ in radius (see the distribution on July 18-23 in Figure 8). The agreement between the orientation of GNSS-azimuths and the most compressive axis of the earthquake suggests that the earthquake-related stress accumulation and the CME should be further examined and separated. The stressed areas triggering fault dislocation before earthquakes observed in this study are significantly larger than the post seismic crustal deformation. We compared the size of stressed areas to the earthquake preparation zones estimated using numerical models and seismicity [34-37]. The size of the earthquake preparation can be approximated by the formula of $R=100.43 \mathrm{M}$, where $\mathrm{R}$ is the radius of the earthquake preparation and $\mathrm{M}$ the magnitude of earthquakes. Accordingly, the radii of the earthquake preparation are $141 \mathrm{~km}$ for the M5 earthquake and $420 \mathrm{~km}$ for the Ludian earthquake, respectively. The unique phenomena of disordered regions surrounded by the aligned areas could indicate a locked fault as the developments of an upcoming earthquake approaches the terminal stage or the critical stage. The regions with a radius of about $250 \mathrm{~km}$ and $600 \mathrm{~km}$ can be clearly identified a few days before these two earthquakes (i.e., the terminal stage) and this in general agrees with the radius of the earthquake preparation zone proposed in [35]. Further studies are required in the future to compare the observed locked zone in the critical stage to a potential earthquake preparation zone.

\section{Conclusions}

In this study, we found that the crustal deformation exhibits a disorder-alignment-disorder sequence of the GNSS-azimuths days before the Ludian earthquake in China. The sequence is similar to the observation of the seismo-deformation anomaly two months before the Tohoku-Oki earthquakes in Japan [23] and tens of days before several earthquakes in the Taiwan region [21,22,24]. An agreement between the orientations of the GNSS-azimuths and the direction of the maximum compressive axis of the two earthquakes suggests that the alignment is seismogenic. Thus, the sequence could be utilized to identify crustal seismo-deformation signals in the terminal stage of material failure of earthquakes in distinct areas of the world. The disordered region surrounded by the aligned areas implies the general area of the locked zone, which is apparently approaching the terminal stage of an earthquake. Compared to what we have done in Japan and the Taiwan region, the full picture of the sequence of the GNSS-azimuth cannot be clearly observed there due to the limitation of the land area. However, with a wider coverage of cGNSS stations in China, we can observe the full picture of this sequence, both in the spatial and temporal sense, in this study. Meanwhile, the size of the locked zone roughly supported by an earthquake preparation zone calculated by numerical models [35]. The finding of the 
disordered regions would be useful when one attempts to separate the earthquake-related stress from the cGNSS common-mode error. However, this requires further investigation and is beyond the scope of this study.

The observation of seismo-deformation signals can also be a candidate of a promising anomalous phenomenon. This sheds light on the estimation of earthquake-related stress accumulation in the crust via strain changes in the terminal stage. The estimation is beneficial in understanding groundwater variations, underlying velocity and electrical conductivity. This valuable information is potentially helpful in developing physical mechanisms with distinct physical parameters. Once the physical mechanisms can be supported by distinct physical parameters, it is anticipated that the sesimo-anomalies could become reliable and available.

Author Contributions: Conceptualization, C.-H.C.; methodology, C.-H.C.; validation, X.S., S.W., P.H. and G.M.; formal analysis, X.X.; investigation, S.W. and P.H.; data curation, X.S.; writing-original draft preparation, C.-H.C.; writing-review and editing, C.-H.C. and K.-C.C.; funding acquisition, C.-H.C., K.-C.C. and G.M. All authors have read and agree to the published version of the manuscript.

Funding: This study was supported by the Ministry of Science and Technology of Taiwan (MOST 100-2116-M-194-012-MY3, MOST 107-2119-M-008-018, MOST 108-2116-M-194-012, MOST 108-2119-M-008-001, and MOST 108-2625-M-194-003); and the National Natural Science Foundation of China (41874024) and the project of China Seismic Experimental Site (2018CSES0207). Meanwhile, the research was also funded by the Sichuan earthquake Agency-Research Team of GNSS based on geodetic tectonophysics and mantle-crust dynamics in the Chuan-Dian region (Grant No. 201804). Meanwhile, the research was also funded by the Sichuan earthquake Agency-Research Team of GNSS based on geodetic tectonophysics and mantle-crust dynamics in the Chuan-Dian region (Grant No. 201804).

Conflicts of Interest: The authors declare no conflict of interest. The funders had no role in the design of the study; in the collection, analyses, or interpretation of data; in the writing of the manuscript, or in the decision to publish the results.

\section{References}

1. Wdowinski, S.; Bock, Y.; Zhang, J.; Fang, P.; Genrich, J. Southern California permanent GPS geodetic array: Spatial filtering of daily positions for estimating coseismic and postseismic displacements induced by the 1992 Landers earthquake. J. Geophys. Res. Solid Earth 1997, 102, 18057-18070. [CrossRef]

2. vanDam, T.; Wahr, J.; Milly, P.C.D.; Shmakin, A.B.; Blewitt, G.; Lavallée, D.; Larson, K.M. Crustal displacements due to continental water loading. Geophys. Res. Lett. 2001, 28, 651-654. [CrossRef]

3. Tsai, M.-C.; Yu, S.-B.; Shin, T.-C.; Kuo, K.-W.; Leu, P.-L.; Chang, C.-H.; Ho, M.-Y. Velocity Field Derived from Taiwan Continuous GPS Array (2007 - 2013). Terr. Atmos. Ocean. Sci. 2015, 26, 527-556. [CrossRef]

4. Márquez-Azúa, B.; DeMets, C. Crustal velocity field of Mexico from continuous GPS measurements, 1993 to June 2001: Implications for the neotectonics of Mexico. J. Geophys. Res. 2003, 108, 1-20. [CrossRef]

5. Seeber, G. Satellite Geodesy: Foundations, Methods, and Applications; Walter de Gruyter GmbH \& Co.: Berlin, Germany, 1993.

6. Moore, D.S.; McCabe, G.P. Introduction to the Practice of Statistics, 2nd ed.; W. H. Freeman and Company: New York, NY, USA, 1993.

7. Jiang, W.; Li, Z.; van Dam, T.; Ding, W. Comparative analysis of different environmental loading methods and their impacts on the GPS height time series. J. Geod. 2013, 87, 687-703. [CrossRef]

8. He, X.; Hua, X.; Yu, K.; Xuan, W.; Lu, T.; Zhang, W.; Chen, X. Accuracy enhancement of GPS time series using principal component analysis and block spatial filtering. Adv. Sp. Res. 2015, 55, 1316-1327. [CrossRef]

9. Dong, D.; Fang, P.; Bock, Y.; Webb, F.; Prawirodirdjo, L.; Kedar, S.; Jamason, P. Spatiotemporal filtering using principal component analysis and Karhunen-Loeve expansion approaches for regional GPS network analysis. J. Geophys. Res. Solid Earth 2006, 111. [CrossRef]

10. Blewitt, G. GPS and Space-Based Geodetic Methods. In Treatise on Geophysics; Schubert, G., Ed.; Elsevier: Amsterdam, The Netherlands, 2007; pp. 351-390. ISBN 9780444527486.

11. Huang, N.E.; Wu, Z. A Review on Hilbert-Huang Transform: Method and Its Applications. Rev. Geophys. 2008, 46, 1-23. [CrossRef] 
12. Huang, N.E.; Shen, Z.; Long, S.R.; Wu, M.C.; Shih, H.H.; Zheng, Q.; Yen, N.-C.; Tung, C.C.; Liu, H.H. The empirical mode decomposition and the Hilbert spectrum for nonlinear and non-stationary time series analysis. Proc. R. Soc. London A Math. Phys. Eng. Sci. 1998, 454, 903-995. [CrossRef]

13. Lees, J.M. Reshaping spectrum estimates by removing periodic noise: Application to seismic spectral ratios. Geophys. Res. Lett. 1995, 22, 513-516. [CrossRef]

14. Crawford, W.C.; Webb, S.C. Identifying and Removing Tilt Noise from Low-Frequency $(<0.1 \mathrm{~Hz})$ Seafloor Vertical Seismic Data. Bull. Seismol. Soc. Am. 2000, 90, 952-963.

15. Amante, C.; Eakins, B.W. ETOPO1 1 Arc-Minute Global Relief Model. Available online: https://ngdc.noaa. gov/mgg/global/global.html (accessed on 30 June 2016).

16. Voight, B. A method for prediction of volcanic eruptions. Nature 1988, 332, 125-130. [CrossRef]

17. Scholz, C.H.; Sykes, L.R.; Aggarwal, Y.P. Earthquake Prediction: A Physical Basis. Science 1973, 181, 803-810. [CrossRef] [PubMed]

18. Rabotnov, Y. Creep Problems in Structural Members; North-Holland: Amsterdam, The Netherlands, 1969; ISBN 07204235709780720423570.

19. Voight, B. A Relation to Describe Rate-Dependent Material Failure. Science 1989, 243, 200-203. [CrossRef] [PubMed]

20. Scripps Orbital and Permanent Array Center. Available online: http://sopac.ucsd.edu (accessed on 26 March 2020).

21. Chen, C.-H.; Yeh, T.-K.; Liu, J.-Y.; Wang, C.-H.; Wen, S.; Yen, H.-Y.; Chang, S.-H. Surface Deformation and Seismic Rebound: Implications and Applications. Surv. Geophys. 2011, 32, 291-313. [CrossRef]

22. Chen, C.-H.; Wen, S.; Yeh, T.-K.; Wang, C.-H.; Yen, H.-Y.; Liu, J.-Y.; Hobara, Y.; Han, P. Observation of surface displacements from GPS analyses before and after the Jiashian earthquake $(\mathrm{M}=6.4)$ in Taiwan. J. Asian Earth Sci. 2013, 62, 662-671. [CrossRef]

23. Chen, C.-H.; Wen, S.; Liu, J.-Y.; Hattori, K.; Han, P.; Hobara, Y.; Wang, C.-H.; Yeh, T.-K.; Yen, H.-Y. Surface displacements in Japan before the 11 March 2011 M9.0 Tohoku-Oki earthquake. J. Asian Earth Sci. 2014, 80, 165-171. [CrossRef]

24. Chen, C.-H.; Yeh, T.-K.; Wen, S.; Meng, G.; Han, P.; Tang, C.-C.; Liu, J.-Y.; Wang, C.-H. Unique Pre-Earthquake Deformation Patterns in the Spatial Domains from GPS in Taiwan. Remote Sens. 2020, 12, 366. [CrossRef]

25. Molchan, G.M. Structure of optimal strategies in earthquake prediction. Tectonophysics 1991, 193, $267-276$. [CrossRef]

26. Han, P.; Hattori, K.; Zhuang, J.; Chen, C.H.; Liu, J.Y.; Yoshida, S. Evaluation of ULF seismo-magnetic phenomena in Kakioka, Japan by using Molchan's error diagram. Geophys. J. Int. 2017, 404, 482-490. [CrossRef]

27. Robinson, R.; McGinty, P.J. The enigma of the Arthur's Pass, New Zealand, earthquake: 2. The aftershock distribution and its relation to regional and induced stress fields. J. Geophys. Res. Solid Earth 2000, 105, 16139-16150. [CrossRef]

28. Zeng, X.; Lin, Y.; Chen, W.; Bai, Z. Multiple seismo-anomalies associated with the M6.1 Ludian earthquake on August 3, 2014. J. Asian Earth Sci. 2015, 114, 352-361. [CrossRef]

29. Mouyen, M.; Canitano, A.; Chao, B.F.; Hsu, Y.-J.; Steer, P.; Longuevergne, L.; Boy, J.-P. Typhoon-induced ground deformation. Geophys. Res. Lett. 2017, 44, 11004-11011. [CrossRef]

30. Global Geophysical Fluids Service of IERS. Available online: http://loading.u-strasbg.fr (accessed on 26 March 2020).

31. National Institute of Informatics. Available online: http://agora.ex.nii.ac.jp/digital-typhoon/summary/wnp/s/ 201409.html.ja (accessed on 26 March 2020).

32. Dong, D.; Fang, P.; Bock, Y.; Cheng, M.K.; Miyazaki, S. Anatomy of apparent seasonal variations from GPS-derived site position time series. J. Geophys. Res. Solid Earth 2002, 107, ETG-9. [CrossRef]

33. Yan, H.; Chen, W.; Zhu, Y.; Zhang, W.; Zhong, M. Contributions of thermal expansion of monuments and nearby bedrock to observed GPS height changes. Geophys. Res. Lett. 2009, 36, 1-5. [CrossRef]

34. Dobrovolsky, I.P.; Gershenzon, N.I.; Gokhberg, M.B. Theory of electrokinetic effects occurring at the final stage in the preparation of a tectonic earthquake. Phys. Earth Planet. Inter. 1989, 57, 144-156. [CrossRef] 
35. Dobrovolsky, I.P.; Zubkov, S.I.; Miachkin, V.I. Estimation of the size of earthquake preparation zones. Pure Appl. Geophys. PAGEOPH 1979, 117, 1025-1044. [CrossRef]

36. Keilis-Borok, V.I.; Kossobokov, V.G. Premonitory activation of earthquake flow: Algorithm M8. Phys. Earth Planet. Inter. 1990, 61, 73-83. [CrossRef]

37. Bowman, D.D.; Ouillon, G.; Sammis, C.G.; Sornette, A.; Sornette, D. An observational test of the critical earthquake concept. J. Geophys. Res. Solid Earth 1998, 103, 24359-24372. [CrossRef]

(C) 2020 by the authors. Licensee MDPI, Basel, Switzerland. This article is an open access article distributed under the terms and conditions of the Creative Commons Attribution (CC BY) license (http://creativecommons.org/licenses/by/4.0/). 